\title{
A model to facilitate collaborative social support for pregnant students in secondary schools
}

This article was published in the following Dove Press journal:

Journal of Multidisciplinary Healthcare

28 September 2017

Number of times this article has been viewed

\author{
Sogo F Matlala \\ Department of Public Health, \\ University of Limpopo, Sovenga, South \\ Africa
}

\begin{abstract}
Pregnancy among secondary school students remains a public health problem and is associated with school dropout as well as poor maternal and child health outcomes. Schools in South Africa no longer expel pregnant students as was the case before 2000. Instead, the government encourages them to remain in class to complete their education, but pregnant students often face stigma, and some drop out of school as a result. To remain in class and access antenatal care, pregnant students require social support from teachers, parents and professional nurses. Unfortunately, teachers, parents and professional nurses support pregnant students on an ad hoc basis, and this calls for a model to facilitate collaborative social support. The purpose of this paper is to present and describe a model to facilitate collaborative social support for pregnant students attending secondary schools in South Africa, using the model description steps of Chinn and Kramer. The model is designed as a tool to enable pregnant students to remain in school, attend antenatal care and in the end, deliver healthy babies. The professional nurse, as a member and leader of the school health team which visits secondary schools to provide a package of school health services, is the agent or facilitator of the model.
\end{abstract}

Keywords: communication, health team, learner pregnancy, maternal and child health, school health services, social network

\section{Introduction}

In South Africa, secondary school students who fall pregnant are no longer expelled as was the case before 2000. Instead, the government encourages them to remain in class to complete their education, but pregnant students often face stigma and some drop out of school as a result. ${ }^{1-3}$ Those who stay miss some classes when they have to attend antenatal care (ANC) or miss their ANC appointments to attend classes. In many ways, pregnancy among secondary school students in South Africa, as in other countries, remains a public health and educational challenge that requires a collaborative intervention of professional nurses, teachers, school mates and parents to support these students to remain in school and access ANC. ${ }^{4}$ Such collaborative social support is lacking, and teachers, school mates, parents and professional nurses support pregnant students on an ad hoc basis, where some parents accompany their pregnant daughters to school while some teachers assist with classes they missed while attending ANC. ${ }^{5-9}$

The literature on pregnancy among secondary school students in the country focuses mainly on prevention of pregnancy and on the perceived disadvantages of pregnancy for such students. ${ }^{2,10-14}$ However, no published studies were found on social support for secondary school students who were already pregnant. This study attempts to fill this
Correspondence: Sogo Matlala Department of Public Health, University of Limpopo, Private Bag XI 106, Sovenga, 0727, South Africa

Tel +270152683404

Fax +270152683384

Email France.Matlala@ul.ac.za 
gap by offering a model for systematic collaborative social support for pregnant students in secondary schools.

School health services in South Africa are delivered by multidisciplinary school health teams based at primary health care (PHC) facilities, who visit schools on specified dates. Professional nurses lead these teams; other team members are health promoters and assistant nurses..$^{15}$ Teachers and some parents assist school health teams during their visits to schools. The package of comprehensive health services provided by school health teams does not include ANC for pregnant students; there is no referral from the school health teams to the PHC clinics for ANC, so pregnant students attend ANC at the local PHC clinics on their own. ${ }^{16}$ This lack of referral becomes a challenge for pregnant students when they want to access ANC outside school hours, as some PHC clinics are closed, and if they need to attend during school hours, they miss some classes.

This paper presents and describes a model to facilitate collaborative social support for pregnant students attending secondary schools in South Africa, using the model description steps of Chinn and Kramer. ${ }^{17}$ The model is designed as a tool to enable pregnant students to remain in school, attend ANC and in the end, deliver healthy babies. A model is viewed as a drawing of reality showing relationships between issues and helps people to objectively structure the way they view a situation, event or group of people. It can be used to plan for or intervene in a particular health problem. ${ }^{17}$ Facilitation refers to an empowering process of enabling, furthering, promoting and easing actions by paving the way and oiling the wheels to speed up things, while providing supportive efforts by showing ways to overcome barriers. ${ }^{18}$. Social support is the help and encouragement given to people facing difficulties by those in the social network, so that individuals facing challenges can succeed in achieving their goals. ${ }^{18} \mathrm{~A}$ social network refers to the web of social relationships that surround individuals or linkages between people who provide social support. ${ }^{19}$

\section{Materials and methods}

The model is presented and described here following the recommendations of Chinn and Kramer, ${ }^{17}$ Fawcett and DeSantoMadeya ${ }^{20}$ as well as Dickoff et al. ${ }^{21} \mathrm{~A}$ model is described to enhance understanding of its components and the way it works. The process of describing a model is a critical reflection which involves asking questions and answering them.

Chinn and Kramer recommend the description of a model to contain the purpose, setting, relationships, concepts, assumptions as well as the structure and process of the model.
Different people or groups can find different purposes in a single model, depending on how they use it or benefit from its use; therefore, a model can be useful to an individual, a family, a group in the community or the whole community. Relationships are links between concepts in a model. The structure refers to the general arrangement of concepts in a model and emerges during the exploration of the link between the concepts. ${ }^{17}$

The assumptions are discussed in line with the nursing metaparadigm of people, environment, health and nursing proposed by Fawcett and DeSanto-Madeya. ${ }^{20}$ People are the individuals, families, communities and other groups that become the recipients of nursing interventions, while the environment represents the social and physical surroundings of the person and the health settings where nursing takes place, which includes the person's home, community and health facilities. Health, on the other hand, is the person's state of well-being, while nursing is the goals and actions taken by nurses in conjunction with human beings and the outcomes of those actions. Nursing refers to goals and actions taken by the professional nurses in conjunction with others who play a part in the social structure of the pregnant student and the outcomes of those nursing actions.

The concepts that drive this model are the agent, procedure, recipient, context and outcome. ${ }^{21}$ This model serves as the basis for development and description of detailed guidelines for the operationalization of the model.

\section{Discussion}

The model to facilitate collaborative social support for pregnant students attending secondary schools in South Africa is described under the purpose, setting, people and relationships, assumptions as well as structure and process.

\section{Purpose}

The purpose of the model presented in this paper is to coordinate and strengthen social support needed by the pregnant student to remain in school and access ANC. It coordinates and maximizes the support that teachers, parents and professional nurses are willing to offer to a pregnant student.

\section{Setting}

The setting consists of the environment where the pregnant student lives and the context where the model operates.

\section{Environment}

The environment refers to the distance that some pregnant students travel to reach school, the health and safety condi- 
tions at school and the physical activities in which students engage in while at school. Some students live more than 3 $\mathrm{km}$ away from their schools and are not provided with either scholar transport or hostel accommodation by the schools, as required. ${ }^{22}$ Some walk, while others use taxis, busses, bicycles, motorbikes or private cars to reach their schools. Walking can take up to 90 minutes for some students. Additionally, there are unsafe conditions in some schools in the form of overcrowded classes, lack of safety and security, violence, and lack of water, sanitation and toilets. The infrastructure is not always adequate in that some schools have no space for a school health team to provide health services or to use as sickroom for students who need observation or a place they can be kept while arrangements are made to take them to the local PHC clinic or hospital. Hospitals and PHC clinics where ANC is provided are sometimes within walking distance from some schools; but in other cases, the schools and health facilities are far apart. Some schools have multiple floor buildings without lifts, requiring students to walk up and down flights of stairs as they change classes. The environment also refers to the home of the pregnant student and the local PHC clinic where she attends ANC.

\section{The context}

The model is designed for the South African secondary school context, which comprises legal framework and physical elements. While at school, students engage in various forms of physical activity either as play during school breaks, as a requirement for Physical Education and Training or as form of punishment for coming late to school. ${ }^{23}$ Due to the banning of corporal punishment at schools, some teachers punish students by making them run around the school or do frog jumps and other forms of severe physical exercise.

The legal framework refers to rules governing school attendance by pregnant students and rules regulating the provision of health services for them. The rules allow pregnant students to continue attending school, but they do not get collaborative social support from teachers, parents and professional nurses. ${ }^{5,7,8}$

\section{People and relationships}

In this model, the key players are the pregnant secondary school student, her teachers, school mates, parents and professional nurses working in school health services and PHC clinics. Relationships are linkages between people and between concepts in a model.
The pregnant student is the recipient who needs and receives social support. She has a dependent relationship with her teachers, school mates, parents and professional nurses for social support in order to remain in class and access ANC. The professional nurse is the agent and facilitator of social support. A professional nurse has a professional relationship with the pregnant student, her teachers and parents. The professional nurse offers expertise to facilitate provision of collaborative social support to promote health. Teachers are supporters and have a professional relationship with the pregnant student and her parents. They provide her with educational support to promote education. Some of her school mates are supporters and have a peer relationship with the pregnant student. They protect her against stigmatization, castigation and discrimination. Parents are supporters and have a parental relationship with the pregnant student. They provide her with parental support, so that she can remain in class and access ANC. All concepts in this model are linked, and converge to a single concept, "facilitation of social support", which indicates the purpose of the model.

\section{Assumptions}

The driving assumption for the model to be implemented successfully is that a pregnant student will take a decision to remain in school and complete her secondary education while carrying her pregnancy to term until she delivers a healthy child. Parents are willing to support their pregnant daughter and they also want to communicate with teachers and professional nurses. Teachers are willing to support the pregnant student and communicate with parents and professional nurses. The model also assumes that a competent professional nurse is available to facilitate collaborative social support for the pregnant student. Additional assumptions are that the pregnant student has a home, a secondary school and access to a PHC clinic in her community where she will attend ANC. It is further assumed that she has supportive parents and other family members at home, supportive teachers and peers at school, as well as supportive professional nurses at the local PHC clinic. It is also assumed that the pregnant student will not experience serious health problems that will force her to drop out of school, but will attend until she is ready to deliver.

\section{Structure}

This model contains one structure made up of several parts and three phases (Figure 1). 


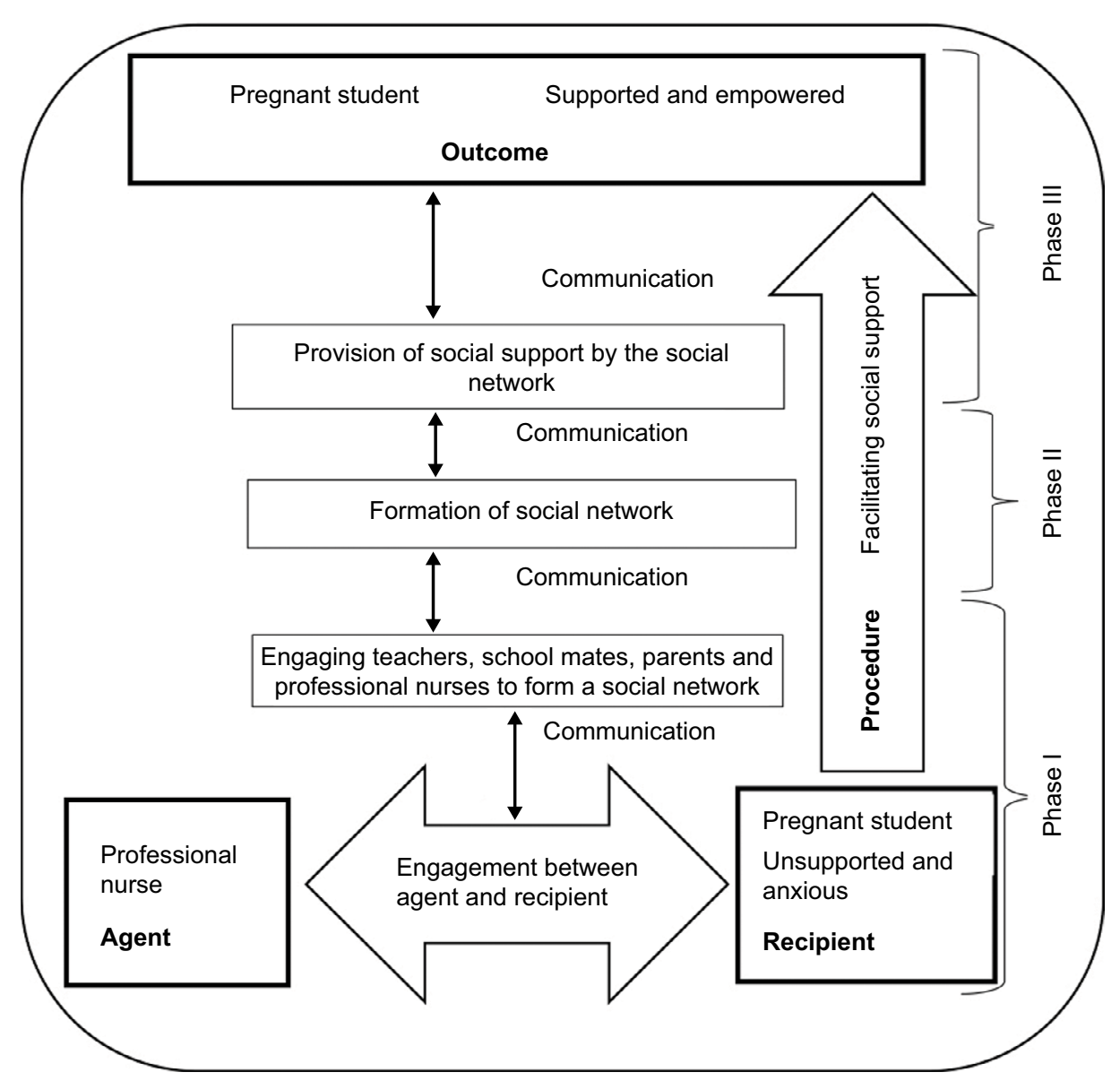

Figure I Model to facilitate social support to pregnant students.

Note: This facilitation of social support (PROCEDURE) takes place in a secondary school (Context). In Phase I, the professional nurse (Agent), as facilitator of social support, identifies the pregnant student and initiates the engagement process and individual communication with her (Recipient) (Phase I). Following identification of her needs for social support, the professional nurse communicates with the pregnant student, her parents, teachers, school mates and the local clinic's professional nurses in order to initiate a social network. In Phase II, the social network is formed, which then provides ongoing social support to the pregnant student. The Outcome (Phase III) is a pregnant student who is supported and empowered to access antenatal care while continuing to attend school.

\section{Process}

\section{Facilitation of social support}

Facilitation of social support refers to a process of making it easy for a pregnant student to receive help that is empowering and enabling, given and communicated by a social network of teachers, school mates, parents and professional nurses to which she belongs, in order to raise her esteem and increase her feelings of being competent to overcome challenges to access education and ANC. The professional nurse initiates the engagement process and individual communication with the pregnant student to identify her needs for social support. The double arrows show communication running throughout the model from Phase I to Phase III. Communication builds relationships and increases access to care. as it promotes partnerships between health care providers, clients and their families. ${ }^{24-26}$

In this model, the professional nurse uses communication, which is one of the values of nursing, to build relationships with the pregnant student, her teachers, parents and professional nurses from the local PHC clinic. ${ }^{25}$ It is through communication that teachers, school mates, parents and professional nurses from the local PHC clinic, as social network members, will understand their roles and expectations. Communication further empowers the pregnant student to enthusiastically participate in the social network available to provide her with social support by voicing her fears and hopes.

\section{Phase I: Initiation of a social network}

The professional nurse is a member and leader of the school health team which visits secondary schools to provide a package of school health services, including health education and counseling on reproductive health services. ${ }^{27}$ The professional nurse becomes aware of pregnant students by receiving referrals from teachers who identified some pregnant students. Other pregnant students approach the professional nurse on their own, as they receive health education and counseling from school health teams.

During individual counseling of the pregnant student, the professional nurse inquires about her teachers, school mates 
and parents who can be approached to offer social support. With the consent of the pregnant student, the professional nurse then approaches the identified teachers, school mates and parents in order to initiate communication with them separately. The professional nurse identifies other professional nurses working at the local PHC clinic where the pregnant student will be referred for ANC. Initiating separate communication with professional nurses at the local PHC clinic is a process that involves making appointments with them and later visiting them at their offices.

The aim of these individual meetings between the professional nurse and stakeholders is to recruit them into a social network and to empower them with skills to provide collaborative social support for pregnant students in secondary schools. Phase I ends when the pregnant student, teachers, school mates, her parents and professional nurses at the local PHC clinic independently understand the need to provide collaborative social support to pregnant students through the formation of a social network.

\section{Phase II: Formation of a social network}

During this phase, the communication process continues and the professional nurse engages the pregnant student, teachers, school mates and her parents as well as the local PHC clinic professional nurses in order to form a social network. The professional nurse organizes teaching sessions and seminars to make them aware of the needs of a pregnant student. The pregnant student, her parents and teachers, as well as the local PHC clinic professional nurses form a social network by discussing the form of support that each one can provide to the pregnant student while working together as a social network. Working together as a social network will enable the forms of support from the various members of the newly formed social network to be harmonized.

As the social network matures, the professional nurse plays a less dominant role and allows its members to take control of the process as they increasingly become knowledgeable. Social network members take control of the process by organizing meetings where they plan and share information on how they can provide collaborative social support to the pregnant student without waiting for the professional nurse to organize those meetings. The professional nurse continues to communicate with the social network members and the pregnant student not only independently, but also as a social network. The professional nurse communicates with the pregnant student during school health visits to find out if she is still participating in the formation of the social network and also to assess her health status. Regular telephone calls, emails and visits to individual members of the social network enable the professional nurse to find out if each member is still prepared to participate in the formation of the social network. This is done as part of monitoring and evaluation of the process, as well as to motivate members to form the social network.

Phase II ends when the social network is formed into a recognized structure ready to provide collaborative social support to an anxious pregnant student by the individual members. A recognized structure is a school-based team, the purpose of which is to provide social support to pregnant students. Members of this team are working in different sectors, but they meet at the school to support pregnant students. The team is recognized by the Department of Health, the parents and the Department of Basic Education as the structure available to provide collaborative social support to pregnant students, while the school health teams continue to provide other components of the school health package.

\section{Phase III: Provision of collaborative social support}

The professional nurse, as the agent and the leader of the school health team, provides counseling to a pregnant student and encourages her to communicate her fears and hopes readily to the social network. The professional nurse further provides information and harmonizes the actions of social network members. Professional nurses at the local PHC clinic support a pregnant student by, during her first ANC visit, planning her subsequent visits outside school hours, so that she does not miss her classes. They should also provide her with a letter informing teachers about her visit to the ANC clinic and the date of the next visit.

The parents provide emotional support to the pregnant student at home by being understanding of her unplanned pregnancy and by refraining from being angry and blaming her for being pregnant. They provide physical and financial support by buying loose-fitting school uniform for her and arranging for her transport to the local clinic for ANC and delivery. Supportive parents should also continue to pay school fees for their pregnant daughter and protect her from negative remarks by some community members. Further, they communicate with the professional nurse and teachers about their daughter's pregnancy. This is done to support her to remain in class and in the end deliver a healthy baby.

Teachers provide emotional support to the pregnant student by encouraging her to remain in class and to communicate her fears and hopes. They accept her at school and consider her pregnancy status during physical activity classes. They should also provide her with educational support on 
the lessons she had missed while attending ANC. Supportive teachers protect pregnant students from sarcastic remarks by some teachers and students at school. Teachers should also communicate with parents and professional nurse about the pregnant student. School mates speak for the pregnant student and support her to endure stigma and discrimination and to remain in class.

The pregnant student, as the recipient and member of the social network, submits herself to the collaborative social support offered by the social network. She communicates her fears and hopes to the professional nurse, her parents and the teachers and, consequently, she gets collaborative social support. She becomes contented as her goals of remaining in class to acquire education and of delivering a healthy child will be achieved. In Phase I, she was anxious but filled with hope of achieving her goals, and in Phase III, she is contented as she is receiving collaborative social support to achieve these goals. Phase III ends with an empowered pregnant student who belongs to a social network. She is empowered to access ANC services while continuing to attend school.

\section{Outcome}

The outcome is an empowered pregnant student. She shows improved coping, a sense of control over life, an increased sense of hope, self-esteem and improved quality of life, which are characteristics of empowerment. ${ }^{28,29}$ As facilitation is an empowering process, the outcome of this model is an empowered pregnant student as well as empowered members of her social network. This positive outcome confirms the recognition that most public health problems, such as pregnancy, among secondary school students call for the contribution of various sectors of the society. ${ }^{30}$

The strength of this model is that a teacher can facilitate it in the absence of a professional nurse. The limitation is that the model has not been evaluated by being implemented in practice; it was only submitted to a panel of experts for evaluation.

\section{Conclusion}

Pregnant students should be supported to remain in class so as to benefit from education. They should also be supported to attend ANC so as to improve maternal and child health. Professional nurses, teachers and parents should work together to support pregnant students. A model is needed to make it possible for these stakeholders to work together. It is important to describe a model clearly to enhance understanding of its components and the way it works.

\section{Acknowledgments}

The author would like to acknowledge the contribution of the Southern African Systems Analysis Center, The National Research Foundation, the Department of Science and Technology in South Africa, as well as the International Institute of Applied Systems in Australia.

\section{Disclosure}

The author reports no conflicts of interest in this work.

\section{References}

1. Department of Education. Measures for the Prevention and Management of Learner Pregnancy. Pretoria: Department of Education; 2007

2. Ramakuela NJ, Lebese TR, Maputle SM, Mulaudzi L. Views of teenagers on termination of pregnancy at Muyexe high school in Mopani District, Limpopo Province, South Africa. Afr J Prm Health Care Fam Med. 2016;8(2):e1-e6.

3. Gyesaw NY, Ankomah A. Experiences of pregnancy and motherhood among teenage mothers in a suburb of Accra, Ghana: a qualitative study. Int $J$ Womens Healt. 2013;5:773-780.

4. Lanjakornsiripan W, Amnatbuddee S, Seejorn K, et al. Contraceptive practices and pregnancy intendedness among pregnant adolescents. Int J Womens Health. 2015;7:315-320.

5. Matlala SF. "It is not good for a pregnant person and it has never been and it will never be": Experiences of parents whose daughters became pregnant while attending secondary schools in Limpopo Province, South Africa. Afr J Phys Health Educ Recr Dance. 2015;(Suppl 1):S22-S36.

6. van Zyl L, van der Merwe M, Chigeza S. Adolescents' lived experiences of their pregnancy and parenting in semi-rural community in the Western Cape. Social Work Maatskaplike Werk. 2015;51(2):150-173.

7. Matlala SF, Nolte AGW, Temane MA. Secondary school teachers' experiences of teaching pregnant learners in Limpopo Province, South Africa. S Afr J Educ. 2014;34(4):1-11.

8. Matlala SF, Nolte AGW, Temane MA. The need for a model to facilitate health for pregnant learners attending secondary schools in South Africa. Mediterr J Soc Sci. 2014;5(25):83-91.

9. Vandeyar S, Runhare T, Dzimiri P, Mulaudzi O. The non-alignment of espoused theories of action to theories-in-use: Sociocultural hurdles to provision of equitable educational opportunity for pregnant students at South African conventional schools. Gender Behavior. 2014;12(1): 6095-6112.

10. de Wet N. Pregnancy and death: An examination of pregnancy related deaths among adolescents in South Africa. S Afr J Child Health. 2016;10(3):151-155.

11. Maxwell GM, Radzilani-Makatu M, Takalani JF. Awareness of prevention of teenage pregnancy amongst secondary school learners in Makhado municipality. Afr J Prm Health Care Fam Med. 2016;8(2):a967.

12. Odimegwu C, Mkwananzi S. Factors Associated with Teenage Pregnancy in sub-Sharan African. Afr J Reprod Health. 2016;20(3):94-107.

13. Masemola-Yende JP, Mataboge SM. Access to information and decision making on teenage pregnancy prevention by females in Tshwane. Curationis. 2015;38(2):1540.

14. Ntsoane RG, Mamogobo PM, Mothiba TM, Lekhuleni ME. Learners' perceptions on teenage pregnancy at Phuti-Nare High School in Sekhukhune District, Limpopo Province, South Africa. Afr J Phys Health Educ Recr Dance. 2015;(Suppl 1):S1-S10.

15. Motshwane F. The integrated school health program: is it working? Oral paper presented at: 6th Child Health Priorities Conference; December 3-5; 2015; University of KwaZulu Natal, Pietermaritzburg, South Africa. 
16. Shung-King M, Orgill M, Slemming W. School health in South Africa: reflections on the past and prospects for the future. South Afri Heal Rev. 2014;59-72.

17. Chinn PL, Kramer MK. Integrated theory and knowledge development in nursing. 8th ed. St Louis: Elsevier Mosby; 2011.

18. Matlala SF. A Model for the Facilitation of Health for Pregnant Students Attending Secondary Schools in Limpopo Province [dissertation]. Pretoria: University of South Africa; 2016.

19. Heaney CA, Israel BA. Social networks and social support. In: Glanz K' Rimer BK, Viswanath K, editors. Health Behavior and Health Education: Theory, Research and Practice. San Francisco: John Wiley and Sons; 2008:189-210.

20. Fawcett J, DeSanto-Madeya S. Contemporary nursing knowledge: Analysis and evaluation of nursing models and theories. 3rd ed. Philadelphia: FA Davis Company; 2013.

21. Dickoff J, James P Wiedenbach E. Theory in a practice discipline. Part 1: Practice oriented theory. Nurs Res. 1968;17(5):415-435.

22. Department of Basic Education. General household survey 2010: Focus on Schooling. Pretoria: Department of Basic Education; 2012.

23. Moyo G, Khewu NPD, Bayaga A. Disciplinary practices in schools and principles of alternatives to corporal punishment strategies. $S$ Afr J Educ. 2014;34(1):1-14.
24. Smith DL. Examining patient-centered communication and access for veterans with disabilities. Mil Med. 2015:180(4):454-463.

25. Boykins AD. Core communication competencies in patient-centered care. $A B N F$ J. 2014;25(2):40-45.

26. Tsiantou V, Pantzou P, Pavi E, Koulierakis G, Kyriopoulos J. Factors affecting adherence to antihypertensive medication in Greece: results from a qualitative study. Patient Prefer Adherence. 2010;4: 335-343.

27. Department of Basic Education and Department of Health. Integrated School Health Policy. Pretoria: Department of Basic Education; 2012

28. Hermansson E, Mårtensson L. Empowerment in midwifery context - a concept analysis. Midwifery. 2011;27(6):811-816.

29. Holmstrong I, Roing M. The relation between patient-centeredness and patient empowerment: a discussion on concepts. Patient Educ Couns. 2010;79(2):167-172.

30. Procter S, Brooks F, Wilson P, Crouchman C, Kendall S. A case study of asthma care in school age children using nurse-coordinated multidisciplinary collaborative practices. J Multidiscip Healthc. 2015;8: $181-188$.
Journal of Multidisciplinary Healthcare

\section{Publish your work in this journal}

The Journal of Multidisciplinary Healthcare is an international, peerreviewed open-access journal that aims to represent and publish research in healthcare areas delivered by practitioners of different disciplines. This includes studies and reviews conducted by multidisciplinary teams as well as research which evaluates the results or conduct of such teams or health

\section{Dovepress}

care processes in general. The journal covers a very wide range of areas and welcomes submissions from practitioners at all levels, from all over the world The manuscript management system is completely online and includes a very quick and fair peer-review system. Visit http://www.dovepress.com/ testimonials.php to read real quotes from published authors. 